\title{
CARTA AL DiRECTOR: ¿Qué nOS aporta LA INVESTIGACIÓN SOBRE EL MORIR Y EL DUELO REALIZADA EN JAPÓN?
}

\begin{abstract}
Como miembros del Grupo de Investigación de Cuidados al Final de la Vida de la Universidad de La Laguna (CUFINVIDA), nuestro objetivo principal se centra en mejorar la atención que se presta por parte de los profesionales en todo aquello que rodea el final de vida y el duelo. Un grupo multidisciplinar al que se siguen sumando profesionales de diversas disciplinas y que hemos acompañado en su formación doctoral. Tenemos una mirada holística del ser humano y nuestros estudios se basan principalmente en investigaciones principalmente de corte cualitativo, con enfoques fenomenológicos, principalmente construccionistas, aunque también las hay con abordajes más positivistas. Nuestro paradigma se sustenta en Enfermería, Fenomenología, Antropología Social y Cultural, Sociología y Psicología Social (García, 2017).

Como ya planteamos en el artículo "Vivencias de las enfermeras ante la muerte" publicado en esta misma revista (Marrero González y García Hernández, 2019), existe escasa producción investigadora y de formación acerca del proceso de morir y sobre el duelo. Así pues,
\end{abstract}

con el fin de seguir mejorando nuestros conocimientos en este área deficitaria, nos hemos planteado describir y reflexionar sobre los resultados de algunas investigaciones de metodología cualitativa realizadas en Japón en los últimos cuatro años y aprender de los resultados de sus investigaciones, así como extraer enseñanzas para reflexionar sobre aspectos que mejorar en nuestro contexto sociocultural occidental, así como orientar nuevas investigaciones.

Siempre es conveniente no solo buscar información de nuestro entorno más cercano, sino también abrir la mente y aprender de lo que se está trabajado en otros países y culturas alejadas de la nuestra. El estudio de cultura empieza con la comprensión de cómo se entienden las personas, un elemento importante del paradigma enfermero. A veces incluso nos sorprenden los resultados puesto que estudiar las historias de lo que la gente dice sobre sí mismos, sobre su trabajo, es como mirar por encima del hombro de la gente cuando nos acercan estas historias y debemos ser capaces de anotarlas con precisión. Esta tarea de comprensión cultural, sobre la que insis- 
te Clifford Geertz con frecuencia, incluye observar lo que ocurre entre las personas en el campo de la intersubjetividad, de modo que comprendamos los intercambios que tienen lugar en la claridad de las interacciones públicas. Cambios que no están vinculados con los misterios de la empatía ni requieren capacidades extraordinarias para entrar en la cabeza de la gente o, peor, en sus almas.

Sin duda, la disyuntiva que se plantea en el momento de utilizar marcos disciplinarios diferentes, sobre un modelo de culturas diferentes, desde las limitaciones que comporta, nos lleva a defender que lo que parece ser un asunto claro en un mundo de sentido común se vuelve en el "Otro, opaco y exótico".

Y nada de estos es ajeno a la muerte y el duelo. Las creencias de que controlamos el mundo, de que éste sea predecible y ordenado confirma según diversos estudios que las personas con buen estado de ánimo tienden a sobrevalorar su capacidad de control, de modo que la expectativa generalizada de control se asocia al ajuste emocional en general y en diferentes culturas.

Partimos de un planteamiento que parte de la premisa de la necesidad de documentarnos aún más sobre el final de vida y el proceso de duelo en el contexto cultural japonés, ya que toda cultura ha de entenderse en sus propios términos y el final de vida no queda al margen. Por otra parte, los investigadores del proceso del duelo, han estudiado muchas cuestiones: la descripción y explicaciones sociológicas, los rasgos clínicos de las reacciones "normales" y "anormales" en las diferentes edades, sexo y las culturas, los programas de prevención, la relación entre el duelo y otras clases de pérdida, así como las diversas formas culturales del luto. Una inmensa madeja de información disponible.

Hamada (2019) ha centrado su interés en fortalecer los vínculos entre el mundo académico (universidades), el mundo de la investigación y la práctica profesional, realizando numerosas investigaciones de carácter cualitativo con grupos de padres que han perdido a sus hijos. Es consciente de que, en Japón, al haber disminuido significantemente la mortalidad infantil, los padres y familias de niños que han perdido hijos pueden sentirse desamparadas con escasos recursos de apoyo. Sus trabajos de corte cualitativo se centran en el estudio de las narraciones de dichos padres. El autor organiza encuentros entre diversas familias con el mismo nexo en común, la muerte de sus hijos, compartiendo recuerdos y fotografías de ellos. De esta forma se crea un espacio de encuentro y significado en el que los padres pueden sentirse acompañados en su dolor y 
además encontrar alivio y consuelo mediante la escucha.

El coordinador de nuestro grupo de investigación, Alfonso Miguel García Hernández, ha basado su trayectoria investigadora en torno a grupos de duelo de padres que han perdido a sus hijos en la isla de Tenerife (España), llevando un abordaje y metodología muy similar, tema al que dedicó su tesis doctoral.

Hamada (2019), organiza también encuentros cada curso académico con padres dolientes y alumnos de Enfermería en la asignatura de Enfermería Pediátrica, lo cual tiene el doble objetivo de ayudar en su formación a los estudiantes y a que los padres sientan escucha y apoyo. De hecho, los padres sienten alivio al haber podido contar las historias de sus hijos y por haber sido escuchados. Por tanto, apreciamos que la labor que hace este profesor puede aportarnos muchas ideas no solo en lo que a investigación se refiere sino también en la docencia en Enfermería y en poder brindar una asistencia más humanizada.

Damos importancia a las narraciones de las personas para poder acércanos a las mismas y a los significados y vínculos que podemos describir a través de las mismas (García Hernández, 2019). Toyama y Honda (2016), describen a través de los resultados que obtuvieron en un artículo de investigación que el enfoque narrativo es efectivo para liberar del rol que desempeñan a los cuidadores de familiares al final de sus vidas y poder así reconocer sus propias emociones. Al dejar a un lado el papel desempeñado de cuidador de su ser querido, fortalecen su vínculo con el familiar que están cuidando y ello les ayuda a expresar sus sentimientos, a llorar y aceptar mejor la pérdida de la persona que cuidan y aman.

Por su parte, Kyota y Kanda (2019), explican que, en el paciente terminal de cáncer, las enfermeras han de captar el significado de la expresión "tengo que aceptarlo" por parte de sus pacientes. Las personas con cáncer terminal se dan cuenta de su situación y tal como describen los autores "su cuerpo les habla" por la enfermedad, les alivia de forma psicológica lo cual repercute en un alivio del estrés de esta etapa final de sus vidas. Asumir su situación y destino les fortalece.

Nos llama la atención como en el trabajo de Kato (2018), el autor se centra en la atención espiritual y como esta ayuda a niños y padres. Kato entrevista a tres capellanes de distintos hospitales de Japón, dos de ellos cristianos y el otro budista. La figura del capellán, señala Kato, ofrece relaciones significativas entre niños, padres y el propio capellán ofreciendo espacios para la compren- 
sión, de modo que la espiritualidad tiene un peso importante vital en la cultura japonesa dadas las características socioculturales y psicológicas de los japoneses.

A propósito de la espiritualidad, Takehiko y Hitomi (2019), recogen del estudio minucioso de narraciones pertenecientes a personas sobrevivientes del gran terremoto que sufrió el este de Japón en marzo de 2011 la conexión espiritual y el reencuentro que tienen los dolientes con sus difuntos en aquella catástrofe natural. Tener sueños con los seres queridos que han perdido, les alivia el dolor ya que hay comunicación y reencuentro con el fallecido.

Así pues, tras este breve repaso sobre estos trabajos de investigación cualitativa realizada en Japón, constatamos lo mucho que podemos aprender sobre el cuidado al final de la vida y sobre el duelo desde el país nipón. Como homo narrator que somos, tenemos similitudes sobre el dolor, sobre la pérdida y sobre el acompañamiento en esta etapa. La parte espiritual es esencial en el holismo y debe ser un asunto a tratar en los dolientes occidentales.

Mirar a Japón sin duda nos ayudará a poder mejorar la humanización de la práctica sanitaria.

Dr. Cristo Manuel Marrero González

Dr. Alfonso Miguel García Hernández 


\section{BIBLIOGRAFÍA}

García Hernández, A.M. (2010). El Significado de Perder un Hijo: la Construcción Discursiva del Duelo de Padres y Madres (Tesis doctoral). Universidad de La Laguna (España).

García Hernández, A. M. (2017). El Grupo de Investigación de la Universidad de La Laguna Cuidados al Final de la Vida. Ene,11 (2), 0-0.

García Hernández, A.M. (2019). Homo Narrator. De cómo contamos Historias a lo Largo de la Vida. Cultura de los Cuidados (Edición digital), 23(55), 4-10. Doi: 10.14198/cuid.2019.55.01

Hamada, Y. (2019). Palliative Care for Children and Grief Care for Families: Practice, Research and Education. 글로벌 건강과 간호, 9(2), 43-47. Doi: 10.35144/ ghn.2019.9.2.43.

Kato, K. (2018). Spiritual Care in Pediatric End of Life Care Settings in Japan from the Perspective of Hospital Chaplain (Master Dissertation) Mills College. California. Estados Unidos.

Kyota, A., Kanda, K. (2019). How to Come to Terms with Facing Death: a Qualitative Study Examining the Experiences of Patients with Terminal Cancer. BMC Palliative Care, 18(1), 33. Doi: 10.1186/ s12904-019-0417-6.

Marrero González, C. M., García Hernández, A. M. (2019). Vivencias de las enfermeras ante la muerte. Ene, 13(2).

Takehiko ITO, Hitomi UDA (2019). The Spirituality of Family Members of those Deceased in the Great East Japan Earthquake: A Text Mining Analysis of Dream Narratives in the Book She came to see me in my Dream. Journal of International Society of Life Information Science, 37(1), 77-79.

Toyama, H., Honda, A. (2016). Using Narrative Approach for Anticipatory Grief Among Family Caregivers at Home. Global Qualitative Nursing Research,0 (3), 1-15 Doi: 10.1177/2333393616682549. 